\title{
Modifikasi Cara Penentuan Kandungan Pasir pada Perancangan Campuran Beton Cara SNI dengan Metode Dreux Gorrise
}

\author{
ADMIRAL HAZEL RABBANI, PRIYANTO SAELAN \\ Jurusan Teknik Sipil Institut Teknologi Nasional Bandung \\ Email: admiralhazelrabbani@gmail.com
}

\begin{abstract}
ABSTRAK
Pencampuran beton cara SNI menunjukkan bahwa kuat tekan hanya dipengaruhi oleh faktor air-semen, sedangkan jika dievaluasi dengan metode Dreux Gorisse diduga akan menghasilkan kuat tekan yang berbeda karena kuat tekan juga dipengaruhi oleh volume pasir. Modifikasi sedemikian rupa pada penentuan pasir dalam agregat gabungan pada cara SNI agar tidak mempengaruhi kuat tekan beton yang akan dihasilkan, dilakukan dengan cara Dreux Gorisse. Pengujian yang dilakukan menggunakan agregat maksimum $10 \mathrm{~mm}$ dan $20 \mathrm{~mm}$, slump rencana $30-60 \mathrm{~mm}$ dan $60-180 \mathrm{~mm}$. Modulus kehalusan pasir yang ditinjau adalah 1,5; 2,0; 2,5; 3,0; dan 3,5. Hasil pengujian modifikasi menggunakan agregat maksimum $10 \mathrm{~mm}$ dengan slump 30-60 mm dan slump 60-180 mm pada modulus kehalusan pasir 1,5; 2,0; dan 2,5 membuktikan kuat tekan beton tidak dipengaruhi oleh kadar volume pasir. Pada pengujian modifikasi menggunakan agregat maksimum $20 \mathrm{~mm}$ dengan slump 30-60 mm dan slump 60-180 mm pada modulus kehalusan pasir 1,5; 2,0; dan 2,5 membuktikan juga bahwa kuat tekan beton tidak dipengaruhi oleh kadar volume pasir.
\end{abstract}

Kata kunci: modulus kehalusan pasir, volume pasir, SNI, kuat tekan

\begin{abstract}
Concrete mixing with the SNI method shows that compressive strength is only influenced by water-cement factors, whereas if evaluated by the Dreux Gorisse method it is assumed that the compressive strength value will be different because the compressive strength is also influenced by the volume of sand. Modifications are made in such a way as to the determination of sand in the combined aggregate on the SNI method so as not to affect the compressive strength of the concrete to be produced by Dreux Gorisse. Tests carried out using a maximum aggregate of $10 \mathrm{~mm}$ and $20 \mathrm{~mm}$, slump plans are used $30-60 \mathrm{~mm}$ and $60-180 \mathrm{~mm}$. The modulus of sand smoothness reviewed was 1.5, 2.0, 2.5, 3.0 and 3.5. The modified test results using a maximum aggregate of $10 \mathrm{~mm}$ with $30-60 \mathrm{~mm}$ slump and $60-180 \mathrm{~mm}$ slump on sand fineness modulus 1,5,2,0, and 2,5 prove that the compressive strength of the concrete is not affected by the sand volume level. In testing the modification using a maximum aggregate of $20 \mathrm{~mm}$ with $30-60 \mathrm{~mm}$ slump and $60-180 \mathrm{~mm}$ slump on sand smoothness modulus of 1.5, 2.0, and 2.5 also prove that the compressive strength of the concrete is not affected by the volume level of the sand.
\end{abstract}

Keywords: sand fineness modulus, sand volume, SNI, compressive strength 


\section{PENDAhUlUAN}

Penentuan kandungan pasir pada perancangan campuran beton cara SNI ditujukan untuk mencapai nilai slump yang direncanakan, dan kandungannya bergantung pada ukuran maksimum agregat kasar, faktor air-semen, dan modulus kehalusan pasir. Untuk mencapai suatu kelecakan yang direncanakan, semakin besar nilai modulus kehalusan pasir, semakin besar pula kandungan pasir dalam agregat gabungan. Dengan demikian berarti semakin besar modulus kehalusan pasir semakin besar pula kandungan volume pasir dalam campuran beton. Hal ini berarti untuk suatu kuat tekan dan kelecakan campuran beton yang direncanakan, dapat dibuat dengan berbagai macam kandungan pasir sesuai dengan modulus kehalusan yang digunakan. Perbedaan volume pasir dalam agregat gabungan akibat perbedaan modulus kehalusan pasir tidak akan mengakibatkan berbedanya kuat tekan yang akan dihasilkan.

Jika hal ini dievaluasi dengan menggunakan formulasi kuat tekan menurut Dreux Gorrise (1979) dalam Thesia (2013) maka diduga akan menghasilkan kuat tekan yang berbeda karena kuat tekan beton tidak hanya dipengaruhi oleh faktor air-semen, tetapi juga dipengaruhi oleh volume pasir. Perbedaan kuat tekan ini dapat menyebabkan kuat tekan yang dihasilkan menjadi lebih rendah dari kuat tekan yang direncanakan. Dengan demikian diperlukan modifikasi cara penentuan kandungan pasir pada perancangan campuran beton cara SNI. Modifikasi yang dilakukan pada penelitian ini adalah dengan menggunakan cara Dreux Gorrise.

\section{TINJAUAN PUSTAKA}

\subsection{Perancangan Campuran Beton Cara SNI}

Salah satu acuan bagi para perencana dalam menentukan komposisi campuran beton adalah dengan menggunakan cara SNI. Dalam SNI 03-2834-2000 menjelaskan tentang persyaratan teknis dan tata cara perancangan proporsi campuran beton untuk menghasilkan mutu beton sesuai dengan yang direncanakan.

Untuk menghitung kuat tekan rata-rata yang direncanakan dapat dihitung dengan menggunakan Persamaan 1 sebagai berikut.

$$
f_{c r}=f_{c}^{\prime}+1,64 S_{r}
$$

halmana:

$f_{c r} \quad=$ kuat tekan beton rata-rata yang ditargetkan pada umur 28 hari [MPa],

$f_{c}^{\prime} \quad=$ kuat tekan beton yang direncanakan pada umur 28 hari [MPa],

$S_{r} \quad=$ deviasi standar rencana $[\mathrm{MPa}]=\sqrt{\frac{\sum_{i=1}^{n}(x i-\bar{x})^{2}}{n-1}}$,

$x_{i} \quad=$ indeks kuat tekan beton masing-masing benda uji,

$\bar{x} \quad=$ kuat tekan beton rata-rata $=\frac{\sum_{i=1}^{n} x i}{n}$.

Untuk mencapai kuat tekan rata-rata yang direncanakan, dibutuhkan faktor air-semen yang didasarkan pada hubungan kuat tekan dan faktor air-semen yang dapat dilihat pada Gambar 1. 


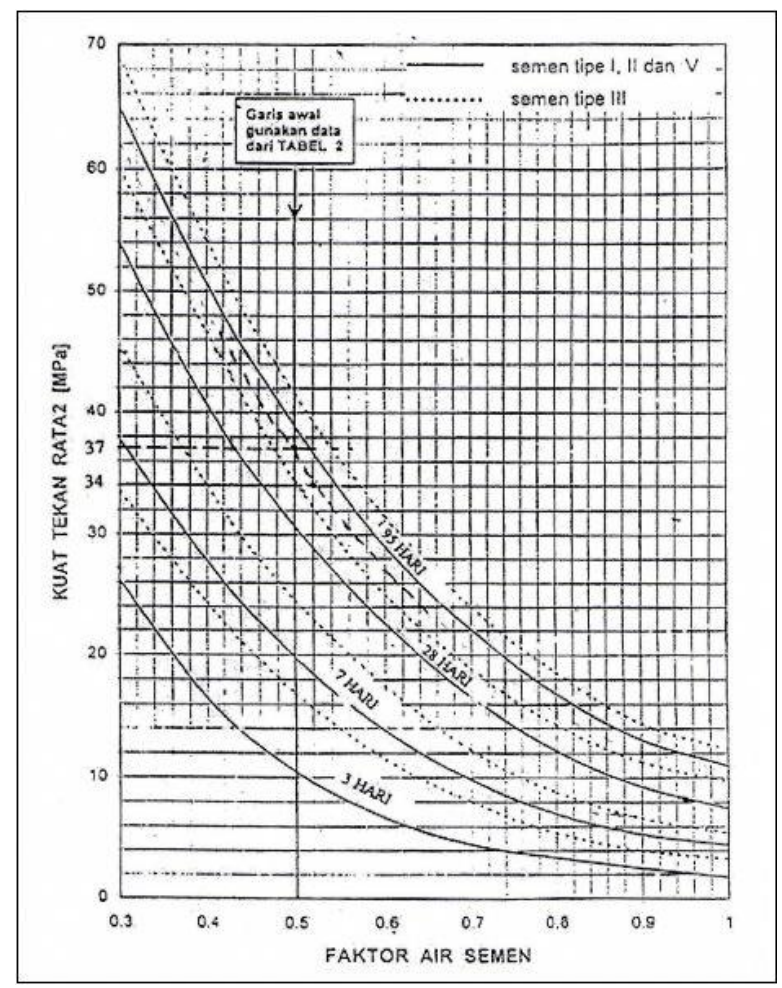

\section{Gambar 1. Hubungan antara kuat tekan beton dan faktor air-semen (Sumber: Badan Standardisasi Nasional, 2000)}

Untuk mencapai kelecakan yang ditargetkan, jumlah air yang dibutuhkan dalam perancangan campuran beton dapat menggunakan Tabel $\mathbf{1}$.

Tabel 1. Perkiraan Kebutuhan Air $\left[\mathrm{kg} / \mathrm{m}^{3}\right]$ dengan Kondisi Agregat Jenuh Kering Permukaan untuk Beberapa Tingkat Kelecakan Beton

\begin{tabular}{|c|c|c|c|c|c|}
\hline \multicolumn{6}{|c|}{ Kebutuhan Air $\left[\mathrm{Kg} / \mathrm{m}^{3}\right]$} \\
\hline \multirow{2}{*}{$\begin{array}{l}\text { Ukuran Besar } \\
\text { Butir Agregat } \\
\text { Maksimum } \\
\text { [mm] }\end{array}$} & \multirow[b]{2}{*}{ Jenis Agregat } & \multicolumn{4}{|c|}{ Slump [mm] } \\
\hline & & 0-10 & $10-30$ & $30-60$ & $60-180$ \\
\hline \multirow{2}{*}{10} & Batu tak dipecahkan & 150 & 180 & 205 & 225 \\
\hline & Batu pecah & 180 & 205 & 230 & 250 \\
\hline
\end{tabular}

(Sumber: Badan Standardisasi Nasional, 2000)

Catatan : Koreksi suhu udara :

Untuk suhu diatas $25^{\circ} \mathrm{C}$, setiap kenaikan $5^{\circ} \mathrm{C}$ harus ditambah air 5 liter per $\mathrm{m}^{2}$ adukan beton.

Jumlah agregat gabungan juga dapat dihitung menggunakan persamaan volume absolut 1 $\mathrm{m}^{3}$ beton dalam Persamaan 2 sebagai berikut.

$$
V_{C}+V_{C A}+V_{F A}+V_{W}+V_{A}=1 \mathrm{~m}^{3}
$$

halmana :

$V_{C} \quad=$ volume absolut semen dalam $1 \mathrm{~m}^{3}$ beton,

$V_{C A} \quad=$ volume absolut agregat kasar dalam $1 \mathrm{~m}^{3}$ beton,

$V_{F A} \quad=$ volume absolut agregat halus dalam $1 \mathrm{~m}^{3}$ beton,

$V_{W} \quad=$ volume absolut air dalam $1 \mathrm{~m}^{3}$ beton,

$V_{A} \quad=$ volume udara dalam $1 \mathrm{~m}^{3}$ beton. 
Penentuan persentase pasir dengan cara SNI ditentukan oleh ukuran butir agregat maksimum, nilai slump, modulus kehalusan (FM), dan faktor air-semen dengan menggunakan grafik pada Gambar 2, atau Gambar 3, atau Gambar 4.

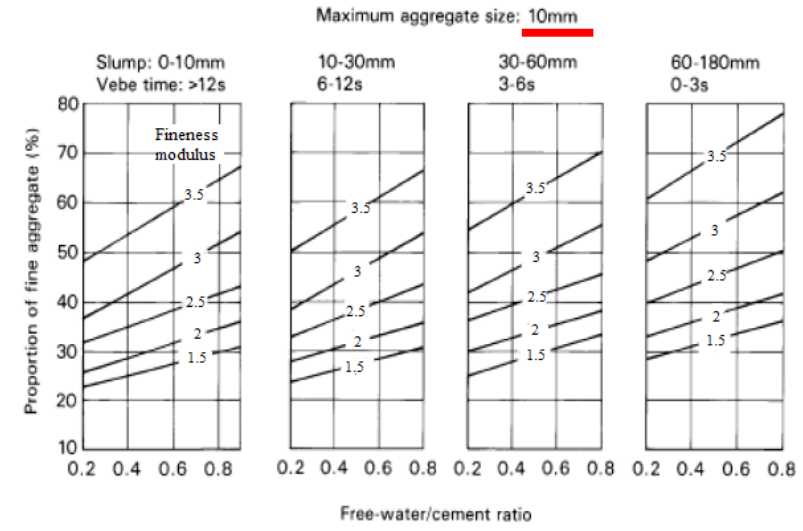

Gambar 2. Persen pasir terhadap kadar total agregat dengan ukuran maksimum agregat $10 \mathrm{~mm}$ (Sumber: Badan Standardisasi Nasional, 2000)

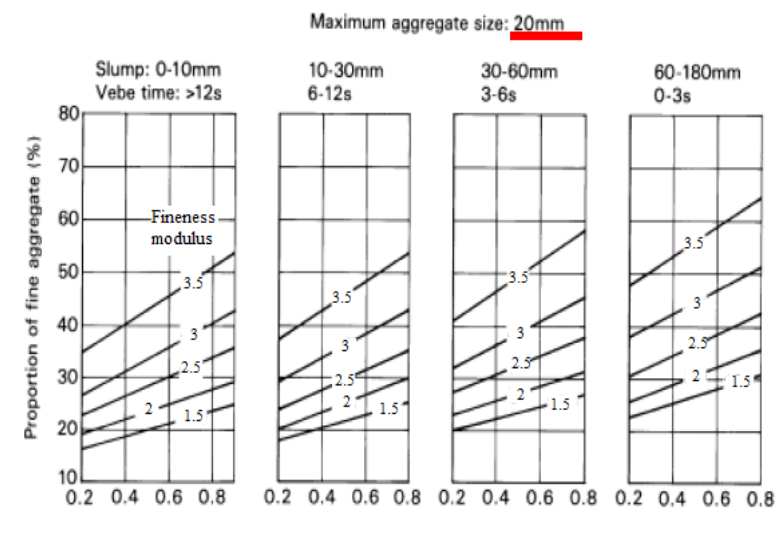

Free-water/cement ratio

Gambar 3. Persen pasir terhadap kadar total agregat dengan ukuran maksimum agregat $20 \mathrm{~mm}$ (Sumber: Badan Standardisasi Nasional, 2000)

\subsection{Perancangan Campuran Beton Cara Dreux Gorrise}

Pada tahun 1979, metode Dreux Gorrise dikembangkan di Perancis berdasarkan pada teori Bolomey dalam merumuskan kuat tekan beton. Perumusan rancangan campuran beton dapat menggunakan Persamaan 3 berikut:

$$
F_{c}=G * F_{p c} *\left(\frac{c}{w}-0,5\right)
$$

halmana:

$F_{c} \quad=$ kuat tekan beton silinder pada umur beton 28 hari [MPa],

$F_{p c} \quad=$ kuat tekan mortar semen pada umur 28 hari [MPa],

$G \quad=$ faktor granular $(0,35-0,65)$,

$c / w \quad=$ faktor air-semen.

Nilai faktor granular $(G)$ dapat dihitung menggunakan Persamaan 4 dari Thesia, Z. (2013): 


$$
V_{\text {pasir }} \quad G=k *
$$

halmana:

$k=$ nilai konstanta yang dapat dilihat pada Tabel 2,

$V_{\text {pasir }}=$ volume pasir yang digunakan dalam $1 \mathrm{~m}^{3}$ beton.

Tabel 2. Nilai $k$ untuk $0,4 \leq G \leq 0,6$

\begin{tabular}{ccc}
\hline No & $\boldsymbol{V}_{\text {pasir }}$ & $\boldsymbol{k}$ \\
& $\boldsymbol{V}_{\text {total agregat }}$ & \\
\hline 1 & $\leq 0,26$ & 3 \\
\hline 2 & $0,26-0,29$ & 2 \\
\hline 3 & $0,29-0,39$ & 1,8 \\
\hline 4 & $0,39-0,43$ & 1,5 \\
\hline 5 & $0,43-0,49$ & 1,8 \\
\hline 6 & $\geq 0,50$ & 1,5 \\
\hline
\end{tabular}

(Sumber: Thesia, Z. 2013)

\subsection{Kajian Pengaruh Kadar Agregat Halus Dalam Agregat Gabungan Terhadap Kekuatan dan Kelecakan Beton}

Proposi pasir dari total agregat gabungan (agregat kasar dan agregat halus) untuk mencapai kelecakan yang direncanakan bergantung dari nilai faktor air-semen, ukuran maksimum agregat, kelecakan (s/ump), dan modulus kehalusan pasir yang digunakan. Untuk suatu kelecakan yang direncanakan, ukuran maksimum agregat yang digunakan, dan faktor airsemen yang dibutuhkan, semakin besar modulus kehalusan pasir semakin besar kandungan pasir dalam agregat gabungan. Hal ini berarti semakin besar modulus kehalusan pasir akan menyebabkan volume pasir yang dibutuhkan bertambah besar pula. Peningkatan volume pasir ini tidak menyebabkan peningkatan kuat tekan beton karena kuat tekan beton hanya ditentukan oleh faktor air-semen pada perancangan campuran beton cara SNI.

Tabel 3. Prediksi Kuat Tekan Beton Pada Umur 28 Hari

\begin{tabular}{ccc}
\hline Campuran & $\begin{array}{c}\text { Cara SNI } \\
{[\mathrm{MPa}]}\end{array}$ & $\begin{array}{c}\text { Cara Dreux Gorrise } \\
{[\mathrm{MPa}]}\end{array}$ \\
\hline 1 & 37 & 32,253 \\
\hline 2 & 37 & 23,594 \\
\hline 3 & 37 & 28,764 \\
\hline 4 & 37 & 34,593 \\
\hline 5 & 37 & 33,069 \\
\hline
\end{tabular}

Pada Tabel 3 terlihat bahwa kuat tekan beton yang dirancang dengan cara SNI berdekatan dengan prediksi kuat tekan beton menggunakan cara Dreux Gorisse hanya terjadi pada campuran 4 yaitu untuk pasir dengan modulus kehalusan 3,0. Berdasarkan prediksi kuat tekan beton yang diperlihatkan pada Tabel $\mathbf{3}$ maka perlu diajukan suatu modifikasi cara penentuan jumlah pasir pada cara SNI sedemikian rupa sehingga kuat tekan beton yang dihasilkan berdekatan dengan kuat tekan beton menurut cara Dreux Gorisse. Modifikasi penentuan pasir dilakukan dengan cara memperbesar persen volume pasir dalam agregat gabungan dari persen pasir yang terdapat pada Gambar 2, Gambar 3, dan Gambar 4. Modifikasi ini didasarkan pada perhitungan modifikasi persen pasir yang terdapat pada Tabel 4, Tabel 5, Tabel 6, dan Tabel 7. 
Tabel 4. Modifikasi Persen Pasir dengan Ukuran Maksimum Agregat 10 mm dan Nilai Slump 60-180 mm

\begin{tabular}{ccccc} 
Campuran & $\begin{array}{c}\text { Cara SNI } \\
\text { [MPa] }\end{array}$ & $\begin{array}{c}\text { Cara Dreux Gorisse } \\
\text { [MPa] }\end{array}$ & $\begin{array}{c}\text { \% Pasir } \\
\text { (SNI) }\end{array}$ & $\begin{array}{c}\text { Modifikasi } \\
\text { \% Pasir }\end{array}$ \\
\hline 1 & 37 & 21,550 & 30,882 & 53,023 \\
\hline 2 & 37 & 27,040 & 38,820 & 53,119 \\
\hline 3 & 37 & 33,587 & 48,325 & 53,235 \\
\hline 4 & 37 & 33,392 & 57,777 & 64,021 \\
\hline 5 & 37 & 38,132 & 66,105 & 64,143 \\
\hline
\end{tabular}

Tabel 5. Modifikasi Persen Pasir dengan Ukuran Maksimum Agregat 10 mm dan Nilai Slump 30-60 mm

\begin{tabular}{crccc}
\hline Campuran & $\begin{array}{c}\text { Cara SNI } \\
\text { [MPa] }\end{array}$ & $\begin{array}{c}\text { Cara Dreux Gorisse } \\
\text { [MPa] }\end{array}$ & $\begin{array}{c}\text { \% Pasir } \\
\text { (SNI) }\end{array}$ & $\begin{array}{c}\text { Modifikasi } \\
\text { \% Pasir }\end{array}$ \\
\hline 1 & 37 & 20,789 & 28,232 & 50,247 \\
\hline 2 & 37 & 25,946 & 35,292 & 50,328 \\
\hline 3 & 37 & 31,941 & 43,528 & 50,422 \\
\hline 4 & 37 & 31,239 & 51,176 & 60,613 \\
\hline 5 & 37 & 36,196 & 59,408 & 60,727 \\
\hline
\end{tabular}

Tabel 6. Modifikasi Persen Pasir dengan Ukuran Maksimum Agregat 20 mm dan Nilai Slump 60-180 mm

\begin{tabular}{ccccc} 
Campuran & $\begin{array}{c}\text { Cara SNI } \\
\text { [MPa] }\end{array}$ & $\begin{array}{c}\text { Cara Dreux Gorisse } \\
\text { [MPa] }\end{array}$ & $\begin{array}{c}\text { \% Pasir } \\
\text { (SNI) }\end{array}$ & $\begin{array}{c}\text { Modifikasi } \\
\text { \% Pasir }\end{array}$ \\
\hline 1 & 37 & 32,253 & 25,710 & 29,494 \\
\hline 2 & 37 & 23,594 & 31,387 & 49,220 \\
\hline 3 & 37 & 28,764 & 38,325 & 49,298 \\
\hline 4 & 37 & 34,593 & 46,174 & 49,387 \\
\hline 5 & 37 & 33,069 & 53,052 & 59,358 \\
\hline
\end{tabular}

Tabel 7. Modifikasi Persen Pasir dengan Ukuran Maksimum Agregat $\mathbf{2 0}$ mm dan Nilai Slump 30-60 mm

\begin{tabular}{ccccc}
\hline Campuran & $\begin{array}{c}\text { Cara SNI } \\
\text { [MPa] }\end{array}$ & $\begin{array}{c}\text { Cara Dreux Gorisse } \\
\text { [MPa] }\end{array}$ & $\begin{array}{c}\text { \% Pasir } \\
\text { (SNI) }\end{array}$ & $\begin{array}{c}\text { Modifikasi } \\
\text { \% Pasir }\end{array}$ \\
\hline 1 & 37 & 28,960 & 22,222 & 28,391 \\
\hline 2 & 37 & 21,692 & 27,777 & 47,378 \\
\hline 3 & 37 & 26,733 & 34,282 & 47,448 \\
\hline 4 & 37 & 31,793 & 40,832 & 47,519 \\
\hline 5 & 37 & 30,239 & 46,666 & 57,100 \\
\hline
\end{tabular}

\section{METODOLOGI PENELITIAN}

\subsection{Prosedur Penelitian}

Prosedur penelitian yang dilakukan dapat dilihat pada Gambar 4. 


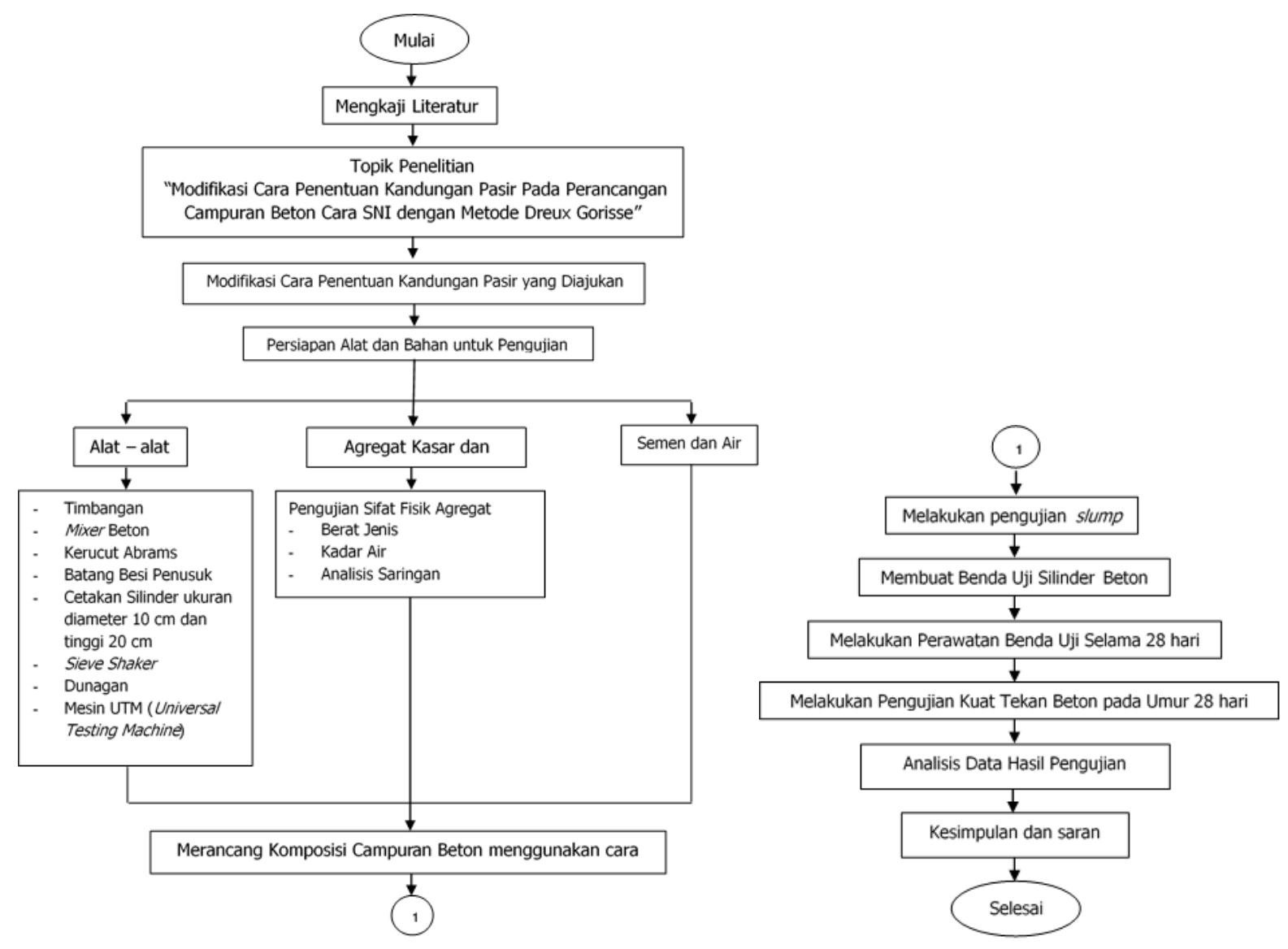

Gambar 4. Bagan alir metode penelitian

\subsection{Data Penelitian}

Data penelitian yang digunakan adalah data primer. Data primer yang digunakan dalam penelitian ini mencakup:

1. Data dari material yang digunakan, didapat dari hasil pengujian material yang hasilnya dapat dilihat pada Tabel 8.

2. Grafik modifikasi penentuan pasir yang diajukan dapat dilihat pada Gambar $\mathbf{5}$ dan Gambar 6.

3. Data komposisi campuran yang digunakan untuk membuat benda uji berbentuk silinder dengan diameter $10 \mathrm{~cm}$ dan tinggi $20 \mathrm{~cm}$ dapat dilihat pada Tabel 9, Tabel 10, Tabel 11, dan Tabel 12.

4. Data hasil pengujian kuat tekan beton silinder beton pada umur 28 hari.

Tabel 8. Hasil Pengujian Sifat Fisik Agregat

\begin{tabular}{lcccc}
\hline \multicolumn{1}{c}{ Parameter } & Semen & $\begin{array}{c}\text { Agregat } \\
\text { Kasar }\end{array}$ & $\begin{array}{c}\text { Agregat } \\
\text { Halus }\end{array}$ \\
\hline Berat jenis kondisi SSD & {$\left[\mathrm{kg} / \mathrm{m}^{3}\right]$} & 3,150 & 2,605 & 2,546 \\
\hline Berat jenis kondisi kering udara & {$\left[\mathrm{kg} / \mathrm{m}^{3}\right]$} & & 2,460 & 2,434 \\
\hline Modulus kehalusan & $(\mathrm{FM})$ & & & 2,657 \\
\hline Kadar air kondisi SSD & {$[\%]$} & & 6,33 & 5,04 \\
\hline Kadar air kondisi kering udara & {$[\%]$} & & 5,44 & 4,38 \\
\hline
\end{tabular}




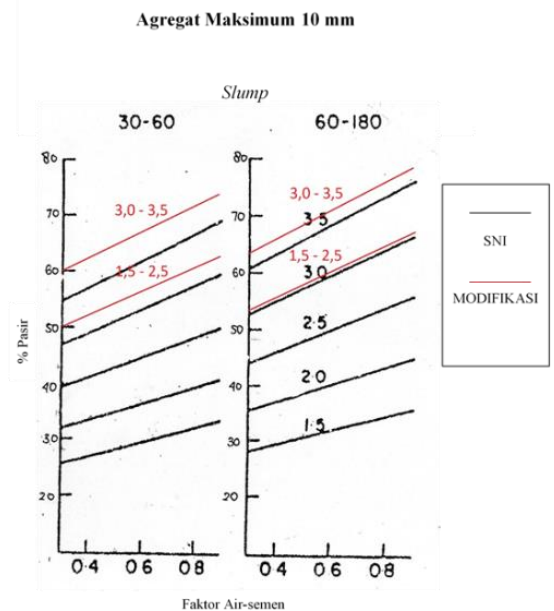

Gambar 5. Modifikasi Persen Pasir Cara SNI untuk Agregat Maksimum 10 mm

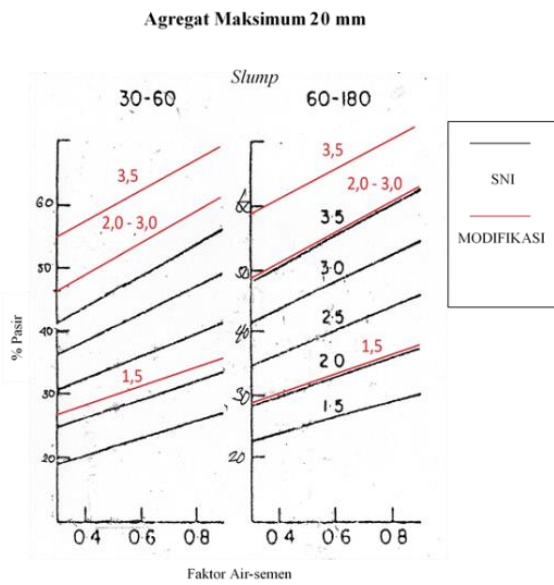

Gambar 6. Modifikasi Persen Pasir Cara SNI untuk Agregat Maksimum 20 mm

Tabel 9. Komposisi $1 \mathrm{~m}^{3}$ Campuran Beton dengan Faktor Air Semen 0,5; Agregat Maksimum 10 mm; dan Slump 30-60 Setelah Dimodifikasi

\begin{tabular}{|c|c|c|c|c|c|c|c|}
\hline \multirow{2}{*}{ Campuran } & \multirow{2}{*}{$\begin{array}{l}\text { Modulus } \\
\text { Kehalusan }\end{array}$} & \multirow{2}{*}{$\begin{array}{c}\text { Semen } \\
{[\mathrm{kg}]}\end{array}$} & \multicolumn{2}{|c|}{ Volume Pasir [m³] } & \multicolumn{2}{|c|}{ Volume Batu Pecah [m³] } & \multirow{2}{*}{$\begin{array}{c}\text { Air (SSD) } \\
{[\mathbf{k g}]}\end{array}$} \\
\hline & & & SNI & Modifikasi & SNI & Modifikasi & \\
\hline 1 & 1,5 & 426,666 & 0,181 & 0,349 & 0,450 & 0,282 & 213,33 \\
\hline 2 & 2,0 & 426,666 & 0,226 & 0,349 & 0,405 & 0,282 & 213,33 \\
\hline 3 & 2,5 & 426,666 & 0,278 & 0,349 & 0,353 & 0,282 & 213,33 \\
\hline 4 & 3,0 & 426,666 & 0,327 & 0,415 & 0,304 & 0,216 & 213,33 \\
\hline 5 & 3,5 & 426,666 & 0,378 & 0,415 & 0,253 & 0,216 & 213,33 \\
\hline
\end{tabular}

Tabel 10. Komposisi $1 \mathrm{~m}^{3}$ Campuran Beton dengan Faktor Air Semen 0,5; Agregat Maksimum 10 mm; dan Slump 60-180 Setelah Dimodifikasi

\begin{tabular}{|c|c|c|c|c|c|c|c|}
\hline \multirow{2}{*}{ Campuran } & \multirow{2}{*}{$\begin{array}{c}\text { Modulus } \\
\text { Kehalusan }\end{array}$} & \multirow{2}{*}{$\begin{array}{c}\text { Semen } \\
{[\mathbf{k g}]}\end{array}$} & \multicolumn{2}{|c|}{ Volume Pasir [m³] } & \multicolumn{2}{|c|}{ Volume Batu Pecah [m³] } & \multirow{2}{*}{$\begin{array}{c}\text { Air (SSD } \\
{[\mathbf{k g}]}\end{array}$} \\
\hline & & & SNI & Modifikasi & SNI & Modifikasi & \\
\hline 1 & 1,5 & 466,666 & 0,188 & 0,355 & 0,411 & 0,243 & 233,33 \\
\hline 2 & 2,0 & 466,666 & 0,236 & 0,355 & 0,363 & 0,243 & 233,33 \\
\hline 3 & 2,5 & 466,666 & 0,293 & 0,355 & 0,306 & 0,243 & 233,33 \\
\hline 4 & 3,0 & 466,666 & 0,349 & 0,422 & 0,249 & 0,177 & 233,33 \\
\hline 5 & 3,5 & 466,666 & 0,399 & 0,422 & 0,200 & 0,177 & 233,33 \\
\hline
\end{tabular}


Tabel 11. Komposisi $1 \mathrm{~m}^{3}$ Campuran Beton dengan Faktor Air Semen 0,5;

Agregat Maksimum 20 mm; dan Slump 30-60 Setelah Dimodifikasi

\begin{tabular}{|c|c|c|c|c|c|c|c|}
\hline \multirow{2}{*}{ Campuran } & \multirow{2}{*}{$\begin{array}{c}\text { Modulus } \\
\text { Kehalusan }\end{array}$} & \multirow{2}{*}{$\begin{array}{c}\text { Semen } \\
\text { [kg] }\end{array}$} & \multicolumn{2}{|c|}{ Volume Pasir $\left[\mathrm{m}^{3}\right]$} & \multicolumn{2}{|c|}{ Volume Batu Pecah $\left[\mathrm{m}^{3}\right]$} & \multirow{2}{*}{$\begin{array}{c}\text { Air (SSD) } \\
\text { [kg] }\end{array}$} \\
\hline & & & SNI & Modifikasi & SNI & Modifikasi & \\
\hline 1 & 1,5 & 380 & 0,151 & 0,214 & 0,518 & 0,455 & 190 \\
\hline 2 & 2,0 & 380 & 0,189 & 0,354 & 0,480 & 0,315 & 190 \\
\hline 3 & 2,5 & 380 & 0,233 & 0,354 & 0,436 & 0,315 & 190 \\
\hline 4 & 3,0 & 380 & 0,277 & 0,354 & 0,392 & 0,315 & 190 \\
\hline 5 & 3,5 & 380 & 0,316 & 0,422 & 0,353 & 0,248 & 190 \\
\hline
\end{tabular}

Tabel 12. Komposisi $1 \mathrm{~m}^{3}$ Campuran Beton dengan Faktor Air Semen 0,5; Agregat Maksimum 20 mm; dan Slump 60-180 Setelah Dimodifikasi

\begin{tabular}{|c|c|c|c|c|c|c|c|}
\hline \multirow{2}{*}{ Campuran } & \multirow{2}{*}{$\begin{array}{c}\text { Modulus } \\
\text { Kehalusan }\end{array}$} & \multirow{2}{*}{$\begin{array}{c}\text { Semen } \\
\text { [kg] }\end{array}$} & \multicolumn{2}{|c|}{ Volume Pasir [m³] } & \multicolumn{2}{|c|}{ Volume Batu Pecah $\left[\mathrm{m}^{3}\right]$} & \multirow{2}{*}{$\begin{array}{c}\text { Air (SSD) } \\
\text { [kg] }\end{array}$} \\
\hline & & & SNI & Modifikasi & SNI & Modifikasi & \\
\hline 1 & 1,5 & 410 & 0,169 & 0,212 & 0,476 & 0,433 & 205 \\
\hline 2 & 2,0 & 410 & 0,206 & 0,355 & 0,439 & 0,290 & 205 \\
\hline 3 & 2,5 & 410 & 0,251 & 0,355 & 0,394 & 0,290 & 205 \\
\hline 4 & 3,0 & 410 & 0,301 & 0,355 & 0,343 & 0,290 & 205 \\
\hline 5 & 3,5 & 410 & 0,346 & 0,418 & 0,299 & 0,227 & 205 \\
\hline
\end{tabular}

\section{HASIL PENELITIAN DAN PEMBAHASAN}

\subsection{Hasil Penelitian}

Hasil pengujian kuat tekan benda uji silinder beton dengan ukuran diameter $10 \mathrm{~cm}$ dan tinggi $20 \mathrm{~cm}$ pada umur 28 hari ditunjukkan pada Tabel 13, Tabel 14, Tabel 15, dan Tabel 16.

Tabel 13. Hasil Pengujian Komposisi $1 \mathrm{~m}^{3}$ Campuran Beton Menggunakan Cara SNI dengan Ukuran Agregat Maksimum $10 \mathrm{~mm}$; Nilai S/ump 30-60 mm; Berat Jenis Pasir 2,546 t/ $\mathrm{m}^{3}$; Berat Jenis Batu Pecah 2,605 t/m³; dan Nilai Faktor Air Semen 0,50

\begin{tabular}{|c|c|c|c|c|c|c|c|}
\hline \multicolumn{3}{|c|}{ Campuran } & 1 & 2 & 3 & 4 & 5 \\
\hline \multicolumn{3}{|c|}{ Modulus Kehalusan Pasir } & 1,5 & 2,0 & 2,5 & 3,0 & 3,5 \\
\hline \multirow{2}{*}{ Pasir } & Semula & \multirow{2}{*}[\%]{} & 28,232 & 35,292 & 43,528 & 51,176 & 59,408 \\
\hline & Tambahan & & 26,472 & 19,412 & 11,176 & 14,116 & 5,884 \\
\hline Semen & & {$\left[\mathrm{m}^{3}\right]$} & 0,804 & 0,804 & 0,804 & 0,804 & 0,804 \\
\hline \multirow{2}{*}{ Air } & Semula & \multirow{2}{*}[\mathrm{kg}/\mathrm{m}^{3}]{} & 64,064 & 64,064 & 64,064 & 64,064 & 64,064 \\
\hline & Tambahan & & 19,506 & 19,506 & 19,506 & 9,713 & 9,713 \\
\hline \multirow{2}{*}{$\begin{array}{l}\text { Volume } \\
\text { Pasir }\end{array}$} & SNI & \multirow{2}{*}[\mathrm{m}^{3}]{} & 0,181 & 0,226 & 0,278 & 0,327 & 0,379 \\
\hline & Modifikasi & & 0,349 & 0,349 & 0,349 & 0,415 & 0,415 \\
\hline
\end{tabular}


Tabel 13. Hasil Pengujian Komposisi $1 \mathrm{~m}^{3}$ Campuran Beton Menggunakan Cara SNI dengan Ukuran Agregat Maksimum $10 \mathrm{~mm}$; Nilai Slump 30-60 mm; Berat Jenis Pasir 2,546 t/ $\mathrm{m}^{3}$; Berat Jenis Batu Pecah 2,605 t// $\mathrm{m}^{3}$; dan Nilai Faktor Air Semen 0,50 lanjutan

\begin{tabular}{|c|c|c|c|c|c|c|}
\hline \multicolumn{2}{|c|}{ Campuran } & 1 & 2 & 3 & 4 & 5 \\
\hline \multicolumn{2}{|c|}{ Modulus Kehalusan Pasir } & 1,5 & 2,0 & 2,5 & 3,0 & 3,5 \\
\hline Volume Batu Pecah & {$\left[\mathrm{m}^{3}\right]$} & 0,282 & 0,282 & 0,282 & 0,216 & 0,216 \\
\hline \multirow{2}{*}{$\begin{array}{l}\text { Prediksi Kuat Tekan } \\
\text { Rencana }\end{array}$} & SNI [MPa] & 37 & 37 & 37 & 37 & 37 \\
\hline & $\begin{array}{c}\text { Modifikasi SNI } \\
{[\mathrm{MPa}]}\end{array}$ & 20,789 & 25,946 & 31,941 & 31,239 & 36,196 \\
\hline $\begin{array}{l}\text { Kuat Tekan Rata-rata } \\
\text { Umur } 28 \text { hari dari } \\
\text { Umur Pengujian }\end{array}$ & [MPa] & 21,432 & 21,221 & 30,345 & 21,890 & 27,251 \\
\hline Slump Aktual & {$[\mathrm{mm}]$} & 20 & 10 & 25 & 0 & 20 \\
\hline Umur Pengujian & [hari] & 28 & 28 & 28 & 21 & 21 \\
\hline
\end{tabular}

Tabel 14. Hasil Pengujian Komposisi $1 \mathrm{~m}^{3}$ Campuran Beton Menggunakan Cara SNI dengan Ukuran Agregat Maksimum $10 \mathrm{~mm}$; Nilai Slump 60-180 mm; Berat Jenis Pasir 2,546 t/m $\mathrm{m}^{3}$; Berat Jenis Batu Pecah 2,605 t/m³; dan Nilai Faktor Air Semen 0,50

\begin{tabular}{|c|c|c|c|c|c|c|c|}
\hline \multicolumn{3}{|c|}{ Campuran } & 1 & 2 & 3 & 4 & 5 \\
\hline \multicolumn{3}{|c|}{ Modulus Kehalusan Pasir } & 1,5 & 2,0 & 2,5 & 3,0 & 3,5 \\
\hline \multirow{2}{*}{ Pasir } & Semula & \multirow{2}{*}{ [\%] } & 30,882 & 38,820 & 48,325 & 57,777 & 66,105 \\
\hline & Tambahan & & 27,938 & 20 & 10,495 & 12,223 & 3,895 \\
\hline Semen & & {$\left[\mathrm{m}^{3}\right]$} & 0,879 & 0,879 & 0,879 & 0,879 & 0,879 \\
\hline \multirow{2}{*}{ Air } & Semula & \multirow{2}{*}[\mathrm{m}^{3}]{} & 70,120 & 70,120 & 70,120 & 70,120 & 70,120 \\
\hline & Tambahan & & 9,395 & 18,830 & 18,830 & 9,236 & 9,196 \\
\hline \multirow{2}{*}{$\begin{array}{l}\text { Volume } \\
\text { Pasir }\end{array}$} & SNI & \multirow{2}{*}[\mathrm{m}^{3}]{} & 0,188 & 0,236 & 0,278 & 0,327 & 0,379 \\
\hline & Modifikasi & & 0,355 & 0,355 & 0,355 & 0,422 & 0,422 \\
\hline \multicolumn{2}{|c|}{ Volume Batu Pecah } & {$\left[\mathrm{m}^{3}\right]$} & 0,243 & 0,243 & 0,243 & 0,177 & 0,177 \\
\hline \multirow{2}{*}{\multicolumn{2}{|c|}{$\begin{array}{l}\text { Prediksi Kuat Tekan } \\
\text { Rencana }\end{array}$}} & SNI [MPa] & 37 & 37 & 37 & 37 & 37 \\
\hline & & $\begin{array}{l}\text { Modifikasi } \\
\text { SNI [MPa] }\end{array}$ & 21,550 & 27,040 & 33,587 & 33,392 & 38,132 \\
\hline \multicolumn{2}{|c|}{$\begin{array}{l}\text { Kuat Tekan Rata-rata } \\
\text { Umur } 28 \text { hari dari } \\
\text { Umur Pengujian }\end{array}$} & a] & 31 & 26,738 & 33,104 & 26,101 & 30,156 \\
\hline \multicolumn{2}{|c|}{ Slump Aktual } & [mm] & 20 & 10 & 13 & 10 & 0 \\
\hline \multicolumn{2}{|c|}{ Umur Pengujian } & [hari] & 21 & 28 & 28 & 28 & 21 \\
\hline
\end{tabular}

Tabel 15. Hasil Pengujian Komposisi $1 \mathrm{~m}^{3}$ Campuran Beton Menggunakan Cara SNI dengan Ukuran Agregat Maksimum $20 \mathrm{~mm}$; Nilai Slump 30-60 mm; Berat Jenis Pasir 2,546 t/ $\mathrm{m}^{3}$; Berat Jenis Batu Pecah 2,605 t/m ${ }^{3}$; dan Nilai Faktor Air Semen 0,50

\begin{tabular}{|c|c|c|c|c|c|c|c|}
\hline \multicolumn{3}{|c|}{ Campuran } & 1 & 2 & 3 & 4 & 5 \\
\hline \multicolumn{3}{|c|}{ Modulus Kehalusan Pasir } & 1,5 & 2,0 & 2,5 & 3,0 & 3,5 \\
\hline \multirow{2}{*}{ Pasir } & Semula & \multirow{2}{*}[\%]{} & 22,222 & 27,777 & 34,282 & 40,832 & 46,666 \\
\hline & Tambahan & & 9,248 & 25,575 & 18,070 & 12,520 & 15,804 \\
\hline Semen & & {$[\mathrm{kg}]$} & 380 & 380 & 380 & 380 & 380 \\
\hline \multirow{2}{*}{ Air } & Semula & \multirow{2}{*}[\mathrm{m}^{3}]{} & 57,052 & 57,052 & 57,052 & 57,052 & 57,052 \\
\hline & Tambahan & & 10,390 & 20,661 & 10,350 & 10,350 & 20,621 \\
\hline
\end{tabular}


Tabel 15. Hasil Pengujian Komposisi $1 \mathrm{~m}^{3}$ Campuran Beton Menggunakan Cara SNI dengan Ukuran Agregat Maksimum 20 mm; Nilai Slump 30-60 mm; Berat Jenis Pasir 2,546 t/ $\mathrm{m}^{3}$; Berat Jenis Batu Pecah 2,605 t/m³; dan Nilai Faktor Air Semen 0,50 lanjutan

\begin{tabular}{|c|c|c|c|c|c|c|c|}
\hline \multicolumn{3}{|c|}{ Campuran } & 1 & 2 & 3 & 4 & 5 \\
\hline \multicolumn{3}{|c|}{ Modulus Kehalusan Pasir } & 1,5 & 2,0 & 2,5 & 3,0 & 3,5 \\
\hline \multirow{2}{*}{$\begin{array}{l}\text { Volume } \\
\text { Pasir }\end{array}$} & SNI & \multirow{2}{*}[\mathrm{m}^{3}]{} & 0,151 & 0,189 & 0,233 & 0,277 & 0,316 \\
\hline & Modifikasi & & 0,214 & 0,354 & 0,354 & 0,354 & 0,422 \\
\hline \multicolumn{2}{|c|}{ Volume Batu Pecah } & {$\left[\mathrm{m}^{3}\right]$} & 0,455 & 0,315 & 0,315 & 0,315 & 0,248 \\
\hline \multirow{2}{*}{\multicolumn{2}{|c|}{$\begin{array}{l}\text { Prediksi Kuat Tekan } \\
\text { Rencana }\end{array}$}} & SNI [MPa] & 37 & 37 & 37 & 37 & 37 \\
\hline & & $\begin{array}{l}\text { Modifikasi } \\
\text { SNI [MPa] }\end{array}$ & 28,960 & 21,692 & 26,733 & 31,793 & 30,239 \\
\hline \multicolumn{2}{|c|}{$\begin{array}{l}\text { Kuat Tekan Rata-rata } \\
\text { Umur } 28 \text { hari dari Umur } \\
\text { Pengujian }\end{array}$} & {$[\mathrm{MPa}]$} & 31,618 & 21,645 & 32,044 & 21,890 & 21,429 \\
\hline \multicolumn{2}{|c|}{ Slump Aktual } & {$[\mathrm{mm}]$} & 60 & 30 & 40 & 15 & 10 \\
\hline \multicolumn{2}{|c|}{ Umur Pengujian } & (hari) & 28 & 28 & 28 & 21 & 28 \\
\hline
\end{tabular}

Tabel 16. Hasil Pengujian Komposisi $1 \mathrm{~m}^{3}$ Campuran Beton Menggunakan Cara SNI dengan Ukuran Agregat Maksimum 20 mm; Nilai Slump 60-180 mm; Berat Jenis Pasir 2,546 t/m ${ }^{3}$; Berat Jenis Batu Pecah 2,605 t/m³; dan Nilai Faktor Air Semen 0,50

\begin{tabular}{|c|c|c|c|c|c|c|c|}
\hline \multicolumn{3}{|c|}{ Campuran } & 1 & 2 & 3 & 4 & 5 \\
\hline \multicolumn{3}{|c|}{ Modulus Kehalusan Pasir } & 1,5 & 2,0 & 2,5 & 3,0 & 3,5 \\
\hline \multirow{2}{*}{ Pasir } & Semula & \multirow{2}{*}[\%]{} & 25,710 & 31,387 & 38,325 & 46,174 & 53,052 \\
\hline & Tambahan & & 6,701 & 23,023 & 16,085 & 8,236 & 11,182 \\
\hline Semen & & {$[\mathrm{kg}]$} & 410 & 410 & 410 & 410 & 410 \\
\hline \multirow{2}{*}{ Air } & Semula & \multirow{2}{*}[\mathrm{m}^{3}]{} & 61,514 & 61,514 & 61,514 & 61,514 & 61,514 \\
\hline & Tambahan & & 9,992 & 19,904 & 9,952 & 9,952 & 19,865 \\
\hline \multirow{2}{*}{$\begin{array}{l}\text { Volume } \\
\text { Pasir }\end{array}$} & SNI & \multirow{2}{*}[\mathrm{m}^{3}]{} & 0,169 & 0,206 & 0,251 & 0,301 & 0,346 \\
\hline & Modifikasi & & 0,212 & 0,355 & 0,355 & 0,355 & 0,418 \\
\hline \multicolumn{2}{|c|}{ Volume Batu Pecah } & {$\left[\mathrm{m}^{3}\right]$} & 0,433 & 0,290 & 0,290 & 0,290 & 0,227 \\
\hline \multirow{2}{*}{\multicolumn{2}{|c|}{$\begin{array}{l}\text { Prediksi Kuat Tekan } \\
\text { Rencana }\end{array}$}} & SNI [MPa] & 37 & 37 & 37 & 37 & 37 \\
\hline & & $\begin{array}{l}\text { Modifikasi } \\
\text { SNI [MPa] }\end{array}$ & 32,253 & 23,594 & 28,764 & 34,593 & 33,069 \\
\hline \multicolumn{2}{|c|}{$\begin{array}{l}\text { Kuat Tekan Rata-rata } \\
\text { Umur } 28 \text { hari dari Umur } \\
\text { Pengujian }\end{array}$} & {$[\mathrm{MPa}]$} & 29,497 & 24,615 & 26,101 & 18,763 & 21,858 \\
\hline \multicolumn{2}{|c|}{ Slump Aktual } & {$[\mathrm{mm}]$} & 80 & 10 & 55 & 10 & 20 \\
\hline \multicolumn{2}{|c|}{ Umur Pengujian } & [hari] & 28 & 28 & 28 & 21 & 28 \\
\hline
\end{tabular}

\subsection{Pembahasan}

Adapun hasil pembahasan dari penelitian yang dilakukan yaitu sebagai berikut:

1. Hasil-hasil pengujian untuk modulus kehalusan pasir $1,5-2,5$ lebih mendekati kuat tekan rencana modifikasi daripada kuat tekan rencana SNI.

2. Pada Tabel 13 yaitu untuk agregat maksimum $10 \mathrm{~mm}$ dan s/ump rencana $30-60 \mathrm{~mm}$, kuat tekan 28 hari hasil uji yang mendekati kuat tekan prediksi dengan cara modifikasi SNI terjadi pada modulus kehalusan pasir 1,5 dan 2,5; sedangkan untuk slump rencana 60-180 mm (Tabel 14) terjadi pada modulus kehalusan pasir 1,5; 2,0; dan 2,5. Hasil pada nilai slump rencana dapat digunakan untuk dugaan bahwa jika penyebab turunnya kuat tekan beton pada s/ump 30-60 mm untuk modulus kehalusan pasir 2,0 tidak terjadi, maka kuat tekannya akan berdekatan dengan kuat tekan prediksi. 
3. Berdasarkan Tabel 15 dan Tabel 16 untuk agregat maksimum 20 mm, slump 30-60 $\mathrm{mm}$ (Tabel 15), dan slump 60-180 mm (Tabel 16), kuat tekan hasil pengujian yang mendekati kuat tekan prediksi dengan cara modifikasi SNI terjadi pada modulus kehalusan pasir 1,$5 ; 2,0$; dan 2,5.

4. Pada modulus kehalusan pasir 3,0 dan 3,5 yang kuat tekannya tidak mencapai kuat tekan prediksi dengan cara modifikasi SNI membutuhkan peningkatan garis modulus kehalusannya pada grafik yang sudah dimodifikasi, dengan naiknya garis modulus kehalusan 3,0 dan 3,5 kadar pasir yang dibutuhkan semakin meningkat dan diduga dapat meningkatkan kuat tekannya.

5. Berdasarkan hasil pengujian s/ump, nilai s/ump yang didapat tidak mencapai nilai s/ump rencana disebabkan oleh agregat yang sangat kering.

\section{KESIMPULAN DAN SARAN}

\subsection{Kesimpulan}

Berdasarkan hasil penelitian dan pembahasan hasil penelitian dapat disimpulkan bahwa hasil modifikasi dapat digunakan untuk modulus kehalusan pasir 1,5; 2,0; dan 2,5; sedangkan untuk modulus kehalusan pasir 3,0 dan 3,5 membutuhkan peninjauan ulang. Dapat disimpulkan juga bahwa kuat tekan beton dipengaruhi oleh kadar volume pasir dalam agregat gabungan.

\subsection{Saran}

Dibutuhkan peninjauan ulang pada grafik modifikasi penentuan pasir untuk garis modulus kehalusan pasir 3,0 dan 3,5 agar dilakukan peningkatan pada garis modulus kehalusannya. Pada pencampuran beton cara SNI juga dibutuhkan peninjauan ulang untuk agregat dalam kondisi kering udara karena sulit untuk mendapatkan kondisi SSD saat di lapangan.

\section{DAFTAR RUJUKAN}

Badan Standardisasi Nasional. (2000). SNI 03-2348-2000 tentang Tata Cara Pembuatan Rencana Campuran Beton Normal. Jakarta: Badan Standardisasi Nasional.

Thesia, Z. (2013). Studi Mengenai Perancangan Campuran Beton Cara Dreux Gorrise. Tugas Akhir. Bandung: Jurusan Teknik Sipil - Institut Teknologi Nasional - Bandung. 